\title{
MULTIPLE ORGAN DYSFUNCTION SYNDROME- CLINICAL PROFILE, ASSOCIATIONS AND OUTCOME IN CRITICALLY ILL CHILDREN AGED 1 MONTH TO 14 YEARS ADMITTED TO PICU IN NOBEL MEDICAL COLLEGE TEACHING HOSPITAL IN BIRATNAGAR
}

\author{
Giri $A^{1^{*}}$, Yadav $S K^{2}$, Sah $V K^{1}$, Niraula $N^{3}$, Singh $B^{4}$
}

\section{Affiliation}

1. Assistant Professor, Department of Pediatrics, Nobel Medical College Teaching Hospital, Biratnagar, Nepal

2. Associate Professor, Department of Pediatrics, Nobel Medical College Teaching Hospital, Biratnagar, Nepal

3. Lecturer, Department of Pediatrics, Nobel Medical College Teaching Hospital, Biratnagar, Nepal

4. Medical Officer, Department of Emergency Medicine, Nobel Medical College, Biratnagar

\section{ARTICLE INFO}

\section{Article History}

Received : 17 February, 2019
Accepted : 25 April, 2019
Published : 30 April, 2019

(c) Authors retain copyright and grant the journal right of first publication with the work simultaneously licensed under Creative Commons Attribution License CC - BY 4.0 that allows others to share the work with an acknowledgment of the work's authorship and initial publication in this journal.

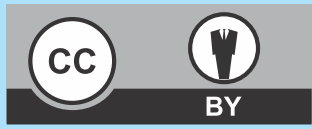

ORA 104

DOI: http://dx.doi.org/10.3126/bjhs.v4i1.23936

\author{
* Corresponding Author \\ Dr. Dr. Arun Giri \\ Assistant Professor \\ Department of Pediatrics \\ Nobel Medical College Teaching Hospital \\ Biratnagar, Nepal \\ ORCID ID : https://orcid.org/0000-0002-7471-3164
}

\section{Citation}

Giri A, Sharma Y, Sah VK, Niraula N. Multiple Organ Dysfunction Syndrome-clinical Profile, Associations And Outcome In Critically III Children Aged 1 Month To 14 Years Admitted To Picu In Nobel Medical College Teaching Hospital In Biratnagar BJHS 2019;4(1)8: 629-633.

\begin{abstract}
Introduction

Multiple organ dysfunction syndrome (MODS), characterized by a progressive physiologic dysfunction involving two or more organ systems after an acute threat to systemic homeostasis, is not a rare entity among patients admitted to the pediatric intensive care units. Despite recent advances made in the medical technology and newer treatment strategies, large numbers of deaths in the PICU are attributable to MODS.
\end{abstract}

\section{Objective}

To describe the clinical profile of MODS among children admitted in PICU and to observe its associations and outcome.

\section{Methodology}

A hospital based prospective observational study was conducted in PICU of Nobel medical college teaching hospital, Biratnagar, Nepal from June 2017- May 2018. Children aged 1 month to 14 years admitted in the PICU with various medical and surgical illnesses were included in the study. All variables defining MODS and the data showing the presence or absence of sepsis were collected within 1 hour of admission (day 0 ) and then every day until transfer or discharge from PICU or until patient's death.

\section{Results}

Out of 150 admissions in the PICU, 103 fulfilled the inclusion criteria, and were enrolled in the study. A total of 53 patients (51\%) developed MODS at some time during their stay at PICU and $88.7 \%$ of them had it at the time of admission. Of 103 cases under study, 26 died (mortality rate $=25.2 \%$ ) and $92.3 \%$ of deaths were attributable to MODS. Children with neurological involvement had the highest risk of death [odds ratio (OR), 19.8; 95\% confidence interval (95\% Cl), 4.37-90.30]. $75.5 \%$ of children with MODS had some sort of infection and $49 \%$ of them had sepsis. Conditions like SIRS, Sepsis, Severe sepsis, Septic shock and ARDS in the study patients were found significantly associated with MODS.

\section{Conclusion}

A MODS is a common clinical entity among patients admitted to the PICU and are associated with significant mortality and morbidity. In children, MODS usually seem to develop early and in a simultaneous way. In developing countries like ours, morbidity and mortality associated with MODS in the PICUs is higher than that in the developed countries. Prevalence of sepsis in children with or without MODS is greater in the developing countries. Sepsis is further responsible for larger number of deaths in PICU.

\section{KEYWORDS}

MODS, PICU mortality, sepsis 


\section{INTRODUCTION}

Multiple Organ Dysfunction Syndrome (MODS) is characterized by a progressive physiologic dysfunction involving two or more organ systems after an acute threat to systemic homeostasis. Risk factors predisposing to the development of MODS include various infectious and noninfectious inflammatory conditions such as sepsis, shock, multiple trauma, burns, accidental poisonings, toxin exposure, and innate immune system activation. Irrespective of the underlying etiology, the morbidity and mortality rates of patients with MODS are high.

Wilkinson et al' initially proposed the diagnostic criteria for organ dysfunctions in critically ill children and defined multiple organ failure as the simultaneous occurrence of failure of at least 2 organ systems. They found an association between increasing number of organ failures and pediatric intensive care unit (PICU) mortality ${ }^{3,4}$ which has been confirmed repeatedly by various other studies. It has been reported from various studies that the number of children who die in the PICUs without reaching criteria for multiple organ dysfunction syndrome (MODS) is very low. ${ }^{4}$

Pediatric and neonatal intensive care is a relatively new medical specialty which has shown marked growth across the world over the last three decades. It is even a newer specialty in the developing countries like ours. Rapid advances in the technology and knowledge have made this progress possible. Intensive care units are thought to make a substantial contribution to the health of children in developed countries. ${ }^{6}$ As compared to the developed countries, children admitted to the PICUs in the developing countries have higher mortality. ${ }^{7,8}$ Multiple organ Dysfunction Syndrome (MODS) in children usually occurs early, and sepsis, which is considered to be the leading cause of MODS in developing countries, increases the mortality. ${ }^{9.11}$

MODS in pediatric patients has been described in various clinical settings, such as general PICU patients, children with sepsis, septic shock, cancers, congenital heart diseases, multiple trauma, burns, accidents and poisonings, liver or bone marrow transplantations etc. Significant variations found in the incidence and mortality rates of MODS between various clinical studies may be possibly due to some variations in case-definitions and case-mix ${ }^{12}$.

To the best of the our knowledge, there has been no published study showing the epidemiology and clinical characteristics of MODS in pediatric population in Nepal. The researcher believes that this study will add to the better understanding of pediatric MODS with respect to the epidemiological characteristics, spectrum of diseases, outcome and factors influencing mortality in children with MODS in Nepal.

\section{METHODOLOGY}

This is a hospital based prospective obsevational study conducted in Nobel medical college and teaching hospital, Biratnagar, Nepal conducted over a period of one year from June 2017 to May 2018. After ethical clearance from institutional review committee, data was collected from 103 consecutively admitted cases in PICU during the study period except those meeting the exclusion criteria. Sample size was determined based on a similar study conducted by Khilnani P et al at New Delhi, India. ${ }^{7}$ After the admission of the patient in PICU, informed consent was taken from the parents/ caretakers after explaining about the study. Patient particulars and demographic information were collected according to the prepared Performa. All neonates, patients who failed to give consent, and children admitted in a post cardiac arrest state were excluded from the study.

Data was collected in a pre-designed Proforma. The International pediatric sepsis consensus conference (IPSCC) criterion was used for defining organ dysfunction. ${ }^{2}$ The data were managed in Microsoft EXCEL Spread Sheet. SPSS 17 software was used for data analysis. Chi square (continuity correlation where applicable), Kruskal Wallis test and independent $t$ test were used. $P$ value was considered significant if it is $<0.05$.

\section{RESULTS}

Out of 103 cases included in the study, 65\% (67 cases) were males and $35 \%$ (36 cases) female with male: female ratio of 1.86:1. Their mean age was 56.7 months. Mean length of PICU stay was 5.45 days. The overall mortality of the study population was $25.2 \%$ ( 26 of 103 cases).

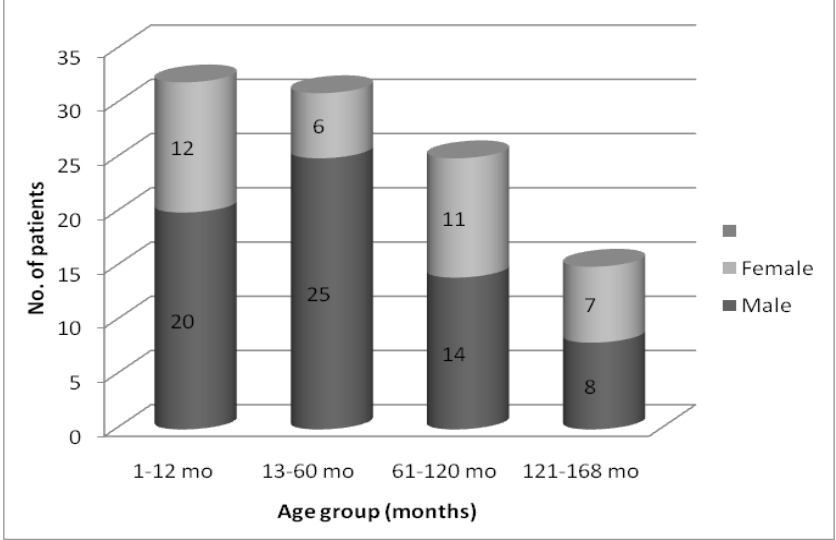

Figure 1: Age and sex distribution Distribution

Of the 103 patients, 51\% had Multiple Organ Dysfunction Syndrome (MODS) out of which $62.2 \%$ (33 cases) were male and $37.8 \%$ (20 cases) female with a male: female ratio of 1.65: 1 . The mean age of patients having MODS was 64.8 months and mean length of stay in PICU was 6.58 days.

\begin{tabular}{|c|c|c|c|c|}
\hline & \multicolumn{4}{|c|}{ MODS } \\
\hline & $\mathbf{N}$ & $\%$ & $\mathbf{n}$ & $\%$ \\
\hline Fever & 57 & 55.3 & 28 & 49.1 \\
\hline Shortness of Breath & 55 & 53.3 & 30 & 54.5 \\
\hline Abnormal body movement & 37 & 35.9 & 21 & 56.8 \\
\hline Altered sensorium & 34 & 33.0 & 22 & 64.7 \\
\hline Vomiting & 33 & 32.0 & 16 & 48.4 \\
\hline Lethargy/Irritability & 24 & 23.3 & 12 & 50.0 \\
\hline Cough & 22 & 21.3 & 10 & 45.5 \\
\hline Pain abdomen & 13 & 12.6 & 9 & 69.2 \\
\hline Loose stools & 9 & 8.7 & 6 & 66.7 \\
\hline Others & 37 & 35.9 & 21 & 56.8 \\
\hline
\end{tabular}


The most frequent symptom among patients admitted in PICU was Fever which occurred in $55.3 \%$ of the patients (57of 103 cases), followed by Shortness of breath in 53.3\% (55 of 103 cases) and Abnormal body movements in 35.9\% (37 of 103 cases). The less frequent ones were Pain abdomen occurring in $12.6 \%$ (13 of 103 cases) and Loose stools in $8.7 \%$ (9 of 103 cases). There was no significant association of the presence or absence of any symptom with the occurrence of $\operatorname{MODS}(p>0.05)$.

\begin{tabular}{|c|c|c|c|c|}
\hline & \multirow[b]{2}{*}{$\mathbf{N}$} & \multirow[b]{2}{*}{$\%$} & \multicolumn{2}{|c|}{ MODS } \\
\hline & & & $\mathbf{n}$ & $\%$ \\
\hline $\begin{array}{l}\text { Respiratory (including pneumonia, } \\
\text { ARDS etc.) }\end{array}$ & 27 & 26.2 & 11 & 40.7 \\
\hline Cardiac & 5 & 4.9 & 4 & 80.0 \\
\hline Neurological & 32 & 31 & 12 & 37.5 \\
\hline Gastrointestinal + hepatobiliary & 2 & 1.9 & 2 & 100.0 \\
\hline Endocrine & 2 & 1.9 & 1 & 50.0 \\
\hline Renal & 2 & 1.9 & 2 & 100.0 \\
\hline Hemato-oncology & 2 & 1.9 & 2 & 100.0 \\
\hline $\begin{array}{l}\text { Other infections (Sepsis, TB, } \\
\text { Enteric fever etc.) }\end{array}$ & 12 & 11.8 & 10 & 83.3 \\
\hline Others ( surgical) & 6 & 5.8 & 3 & 50.0 \\
\hline Others (medical) & 6 & 5.8 & 2 & 33.3 \\
\hline $\begin{array}{l}\text { Accidents (poisoning, burns, } \\
\text { hanging etc.) }\end{array}$ & 7 & 6.9 & 4 & 57.1 \\
\hline
\end{tabular}

The most common diseases needing PICU admissions were Neurological 31\% (32 cases), followed by Respiratory $26.2 \%$ (27 cases), \& other infectious diseases (including Sepsis, TB, Enteric fever etc.) comprising $11.8 \%$ (12 cases). Almost all cases of the gastrointestinal \& hepatobiliary, Renal and hemato-oncological diseases had MODS.

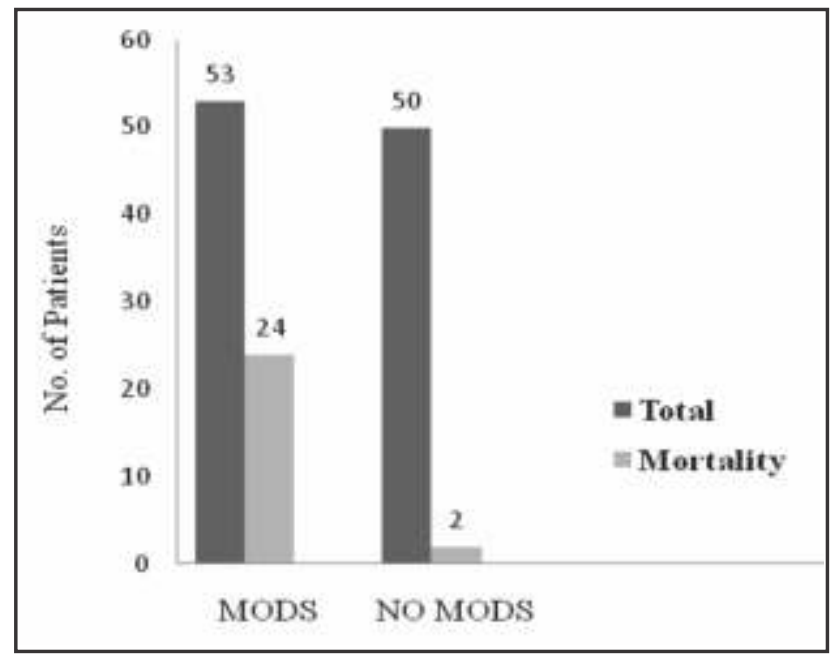

Children with MODS had significantly greater mortality than those who did not have MODS- $45.3 \%$ (24 of 53 cases) compared to $4 \%$ ( 2 of 50 cases) ( $p<0.001$ ).
Table 3: Critical Care Modalities in Patients With or Without MODS

\begin{tabular}{lccccc} 
& \multicolumn{2}{c}{ MODS } & \multicolumn{2}{c}{ NO MODS } & P Value \\
& $\mathbf{n}$ & $\%$ & $\mathbf{N}$ & $\%$ & \\
$\begin{array}{l}\text { Mechanical } \\
\text { Ventilation }\end{array}$ & 34 & 94.4 & 2 & 5.6 & $<0.001$ \\
\hline Vasopressors & 30 & 90.9 & 3 & 9.1 & $<0.001$
\end{tabular}

$94.4 \%$ of the patients (34 of 36 cases) needing Mechanical ventilation and $90.9 \%$ (30 of 33 cases) of those needing Vasopressor support had MODS which is significantly greater than those who didn't have MODS ( $p<0.001)$.

\begin{tabular}{lccccc}
\multicolumn{2}{l}{ Table 3: Antecedents of MODS } & \multicolumn{4}{c}{ MODS } \\
& & \multicolumn{5}{c}{ N } & $\%$ & $\mathbf{n}$ & $\%$ & P \\
& 74 & 71.8 & 40 & 54.1 & 0.39 \\
Infection & 55 & 53.4 & 35 & 63.6 & 0.008 \\
SIRS & 41 & 39.8 & 26 & 63.4 & 0.04 \\
Sepsis & 28 & 27.2 & 26 & 92.9 & $<0.001$ \\
Severe sepsis & 22 & 21.4 & 20 & 90.9 & $<0.001$ \\
Septic shock & 8 & 7.76 & 8 & 100.0 & 0.01 \\
ARDS & & & & &
\end{tabular}

Out of the 103 patients under study, $71.8 \%$ had infection (74 cases), $53.4 \%$ (55 cases) had SIRS, 39.8\% (41 cases) had sepsis, $27.2 \%$ ( 28 cases) had severe sepsis, $21.4 \%$ ( 22 cases) had septic shock and $7.7 \%$ (8 cases) had ARDS. Patients having SIRS, Sepsis, Severe sepsis, Septic shock or ARDS had significant association with the occurrence of MODS.

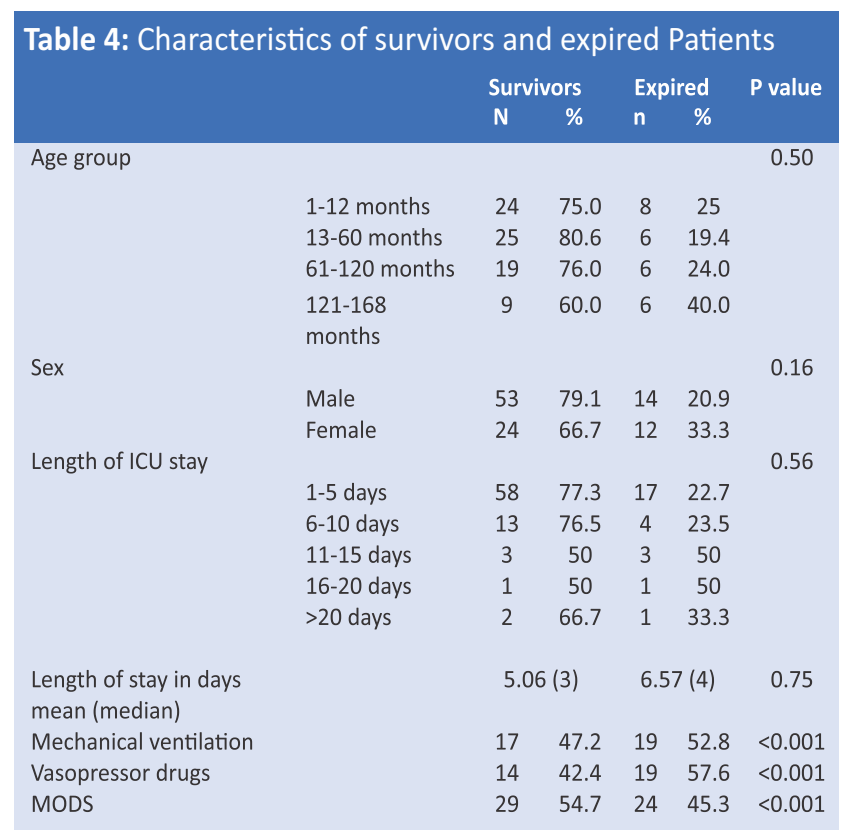

All other characteristics of survivors and expired patients are comparable except that the patients who died after PICU admission needed significantly more critical care support in terms of mechanical ventilation and vasopressor drugs and greater number of them had developed MODS during PICU stay. 


\section{DISCUSSION}

MODS has emerged as a consequence of the advances in intensive care and technological support as the patients who previously would have died can now survive because of the support available to them. Intensive monitoring, mechanical ventilation, dialysis, nutritional support, and other strategies have contributed to greater survival of critically ill children, but they have also allowed more of these children who survive to develop MODS. ${ }^{12}$

In a study period of 12 months, 103 patients were studied. These patients were a heterogeneous group of patients from different parts of the eastern region with various illnesses needing ICU admission. Mean age of our study population was 56.7 months with median of 36 months. Most of the patients admitted were between 1-12 months of age comprising $36.2 \%$ (32 of 103 cases) similar to study conducted by Khilnani et $\mathrm{a}^{13}$ in India (mean age of 42.5 months).

The incidence of MODS in our study was $51 \%$ which is comparable with the study done by Tantalean et $\mathrm{al}^{13}$ in Peru (56.5\%) and a multicentric study by Leteurtre et $\mathrm{al}^{5}$ in France, Canada \& Switzerland (53.4\%).

The overall mortality of our PICU patients was $25.2 \%$ ( 26 of 103 cases), which is close to the study done by Tantalean et $\mathrm{al}^{13}$ in Peru in 2003 who showed a mortality of $25.7 \%$ in their 269 PICU patients under study. Our mortality was however much higher than the other PICUs- Wilkinson et al ${ }^{4}$ in the U.S. (7.5\%), Typoo et $\mathrm{al}^{14}$ in the U.S. (2.8\%), Proulx et al ${ }^{15}$ in Canada (6\%), Leteurtre et $\mathrm{al}^{5}$ in France, Canada \& Switzerland (6.4\%), Khilnani et al ${ }^{12}$ in India (7.9\%). In children with MODS, the mortality was $45.3 \%$ ( 24 of 53 cases) which is comparable with the study conducted by Tantalean et $\mathrm{al}^{13}$ in Peru in 2003 that showed a mortality of $41.6 \%$ among patients with MODS.

The most common disease category needing PICU admission were Neurological 31\% (32 cases), followed by Respiratory $26.2 \%$ (27 cases), \& other infectious diseases (including Sepsis, TB, Enteric fever etc.) comprising 11.8\% (12 cases). This doesn't match with other studies ${ }^{12,13,16}$ where most common disease category was Respiratory.

Of the 103 patients under study; $53.4 \%$ had SIRS, $39.8 \%$ had sepsis, $27.2 \%$ had severe sepsis, $21.4 \%$ had septic shock and $7.7 \%$ had ARDS. It was observed that mortality increased according to the classification: SIRS- $30.9 \%$, sepsis- $31.7 \%$, severe sepsis- $46.4 \%$ and septic shock- $59.1 \%$. In the study by Tantalean et $\mathrm{al}^{13}$, the mortality was found to increase according to the classification in the same order as ours but they had lesser mortality than ours for SIRS (20.6\%) and sepsis (21\%) but greater than ours for Severe sepsis (56.6\%) and septic shock (66.7\%).

When characteristics of survived and observed patients were compared, there was no statistically significant difference in demographic and clinical characteristics like age groups, sex, length of PICU stay (mean and median). However, patients who died during PICU admission needed significantly more critical care support in terms of mechanical ventilation and vasopressor drugs and greater number of them had developed MODS $(p<0.001)$ during PICU stay. The study by Goh YT et a ${ }^{16}$ in Malaysia had showed similar results in terms of non survivors needing more intervention and critical care support and developing MODS.

\section{CONCLUSION}

In this prospective observational study, we observed that MODS is a common clinical entity among patients admitted to the PICU and is associated with significant mortality and morbidity. More than half of the patients under study had MODS and it was attributable to most of the deaths. We had higher incidence of MODS, high overall mortality and increased mortality among patients with MODS as compared to the studies from the developed countries. . Patients with MODS needed significantly more critical care support in terms of interventions and monitoring, mechanical ventilation and vasopressor drugs and had higher mortality as compared to those without MODS. SIRS, Sepsis, Severe sepsis, Septic shock or ARDS were the common antecedents of MODS in children and mortality increased according to the classification: SIRS, sepsis, severe sepsis and septic shock.

\section{RECOMMENDATIONS}

All patients admitted in the PICU should be assessed for the presence of MODS, as it occurs frequently and is associated with high mortality in the PICUs and Efforts should be made to identify established MODS and predict the possibility of developing MODS (SIRS, Sepsis, septic shock, ARDS are the common antecedents) early so that appropriate goal directed therapy and interventions can be instituted to decrease mortality and severity of MODS and improve the functional outcome of PICU patients.

\section{LIMITATIONS OF THE STUDY}

This was the study carried out in single institution with a small sample size. It may not represent the entire population of PICU patients throughout the country. A large prospective study involving as many intensive care units as possible should be carried out to find out the epidemiological profile of MODS in PICUs.

\section{ACKNOWLEDGEMENT}

We would like to acknowledge all our patients and their parents, residents, pediatricians and pathologists for their support, time and participation whose tireless efforts made this study possible.

\section{CONFLICT OF INTEREST}

We declare no conflict of interests.

\section{FINANCIALDISCLOSURE}

None 


\section{REFERENCES}

1. American College of Chest Physicians/ Society of Critical Care Medicine Consensus Conference: Definitions for sepsis and organ failure and guidelines for the use of innovative therapies in sepsis. Crit Care Med. 1992; 20:864-74.

2. Graciano AL, Balko JA, Rahn DS, Ahmad N, Giroir BP. The Pediatric Multiple Organ Dysfunction Score (P-MODS): Development and validation of an objective scale to measure the severity of multiple organ dysfunction in critically ill chidren. Crit Care Med. 2005;33:1484-90.

3. Wilkinson J, Pollack M, Glass N. Mortality associated with multiple organ system failure and sepsis in pediatric intensive care unit. J Pediatr. 1987;111:324-28.

4. Wilkinson J, Pollack M, Ruttimann U. Outcome of pediatric patients with multiple organ system failure. Crit Care Med. 1986;14:271-74.

5. Leteurtre S, Martinot A, Duhamel A, Proulx F, Grandbastien B, Cotting $J$, et al. Validation of the paediatric logistic organ dysfunction score: Prospective, observational, multicentre study. Lancet. 2003;362:192-97.

6. Proulx F, Gauthier M, Nadeau D, et al. Timing and predictors of death in pediatric patients with multiple organ system failure. Crit Care Med. 1994;22:1025-31.

7. Carcillo JA, Fields Al. Clinical practice parameters for hemodynamic support of pediatric and neonatal patients in septic shock. Crit Care Med. 2002;30:1365-78.

8. Angus DC, Linde-Zwirble WT, Lidicker J, et al. Epidemiology of severe sepsis in the United States: analysis of incidence, outcome, and associated costs of care. Crit Care Med. 2001;29: 1303-10.
9. Goldstein B, Giroir B, Randolph A. International pediatric sepsis consensus conference: Definitions for sepsis and organ dysfunction in pediatrics. Pediatr Crit Care Med. 2005;6:2-8.

10. Proulx F, Fayon M, Farrell CA, et al. Epidemiology of sepsis and multiple organ dysfunction syndrome in children. Chest. 1996;109:1033-37.

11. Proulx F, Joyal J, Mariscalco M, Leteurtre S, Leclerc F, Lacroix J. The pediatric multiple organ dysfunction syndrome. Pediatr Crit Care Med. 2009;10(1):12-22.

12. Khilnani P, Sharma D, Zimmerman J. Epidemiology and Peculiarities of Pediatric Multiple Organ Dysfunction Syndrome in New Delhi, India. Intensive Care Med. 2006;32:1856-62.

13. Tantaleán JA, León RJ, Santos AA, Sanchez E. Multiple organ dysfunction syndrome in children. Pediatr Crit Care Med. 2003;4:181-85.

14. Typpo KV, Petersen NJ, Hallman M, et al. Day 1 multiple organ dysfunction syndrome is associated with poor functional outcome and mortality in the pediatric intensive care unit. Pediatr Crit Care Med. 2009;10:562-70.

15. Proulx F, Fayon M, Farrell CA, et al. Epidemiology of sepsis and multiple organ dysfunction syndrome in children. Chest. 1996;109:1033-37.

16. Goh AY, Lum LC, Chan PWK. Paediatric intensive care in Kuala Lumpur, Malaysia: a developing subspecialty. J Trop Pediatr. 1999;45(6):362-64. 